Forthcoming: Food Policy

\title{
Conflict, Food Price Shocks, and Food Insecurity: The experience of Afghan households
}

\author{
Anna D’Souza ${ }^{a} \quad$ Dean Jolliffe ${ }^{b}$
}

March 2013

Abstract: Using nationally-representative household survey data and confidential geo-coded data on violence, we examine the relationship between conflict and food security in Afghanistan. Spatial mappings of the raw data reveal large variations in levels of food insecurity and conflict across the country; surprisingly, high conflict provinces are not the most food insecure. Using a simple bivariate regression model of conflict (violent incidents and persons killed or injured) on food security (calorie intake and the real value of food consumed), we find mixed associations. But once we move to a multivariate framework, accounting for household characteristics and key commodity prices, we find robust evidence that in Afghanistan levels of conflict and food security are negatively correlated. We also find that households in provinces with higher levels of conflict experience muted declines in food security due to staple food price increases relative to households in provinces with lower levels of conflict, perhaps because the former are more disconnected from markets. Gaining a better understanding of linkages between conflict and food security and knowing their spatial distributions can serve to inform policymakers interested in targeting scarce resources to vulnerable populations, for example, through the placement of strategic grain reserves or targeted food assistance programs.

JEL Codes: D12, I3

Keywords: Afghanistan, food security, conflict, nutrition, poverty, spatial distribution

a Corresponding author. D'Souza is a Research Economist at ERS, USDA; adsouza@ers.usda.gov; phone: 001-202-694-5170; fax: 001-202-245-4847;

b Jolliffe is a Senior Economist at the World Bank, and also holds affiliations with the Institute for the Study of Labor (IZA) in Bonn and with the National Poverty Center (NPC) at the Ford School of Public Policy, University of Michigan.

Acknowledgments: The authors wish to thank two anonymous reviewers and the editor, as well as Amanullah Assil, Byron Ponce-Segura, Ismail Rahimi, Matt Shane, and Dan Sumner, for comments. Findings from this analysis provide background information for the World Bank's poverty assessment for Afghanistan, and have informed the Ministry of Economy, Government of Afghanistan (GoA). The authors are grateful to GoA Central Statistics Organization for granting access to the NRVA data and United Nations Department of Safety and Security for allowing access to their restricted incidents data. They also gratefully acknowledge financial support from Australian Aid and the World Bank's Research Support Budget. The views expressed here are those of the authors alone and may not necessarily represent those of ERS-USDA, the World Bank, IZA, or NPC. Paper prepared for presentation at the Agricultural \& Applied Economics Association's 2012 AAEA Annual Meeting, Seattle, Washington, August 12-14, 2012. 


\section{Introduction}

Most wars of the late $20^{\text {th }}$ century and early $21^{\text {st }}$ century are 'food wars', meaning that food is used as a weapon, food systems are destroyed in the course of conflict, and food insecurity persists as a legacy of conflict. (Messer and Cohen, 2006)

Due to the 2008 and 2011 global food price crises, food insecurity has risen to the top of many national and international policy agendas. Given the potential implications for poverty, health and nutrition, and the outbreak of food riots, the impact of high food prices on food security is of concern to governments and aid organizations alike. These issues are particularly salient in conflictafflicted countries where food production and distribution networks are strained and where distributing emergency food aid can be a challenge. The relationship between food insecurity and conflict is complicated. Much of the existing literature (and conventional wisdom) on their relationship suggests that food insecurity can be a consequence of conflict (i.e., due to the destruction of agricultural resources or the disruption of food distribution networks and markets) and also can be a cause of conflict (i.e., through economic and social grievances) (Bora et al., 2010; Messer et al., 2002; Teodosijevic, 2003). In these cases, this harmful cycle can result in chronic food insecurity and can exacerbate poverty.

We investigate variations in food security and the impact of food price shocks within the context of a conflict-afflicted country - Afghanistan. After decades of external and internal conflict, ${ }^{1}$ along with prolonged droughts, Afghanistan has one of the poorest, least well-nourished populations in the world. Nearly 30 percent of the Afghan population do not meet minimum daily food requirements (2,100 kilocalories per person) (Islamic Republic of Afghanistan and the World Bank, 2010). Approximately 60 percent of children under five suffered from chronic malnutrition (stunting) and eight percent suffered from acute malnutrition (wasting) (Johnecheck and Holland, 2007). In 2008 in Afghanistan, due to a confluence of domestic (drought), regional (export bans), and international (food price crisis) factors, the price of wheat flour (the dietary staple) doubled. Such an economic

\footnotetext{
${ }^{1}$ Afghanistan has a long history of conflict involving both intra- and inter-state groups; for an overview of the conflict over the past thirty years, see Giustozzi and Ibrahimi (2012). In this paper we do not distinguish between different actors, rather we define conflict based on incidents of violence in which there are fatalities and/or casualties; more details are provided in the data section.
} 
shock could have serious implications for households in Afghanistan, many of whom are impoverished and live in conflict-afflicted areas.

We use nationally-representative household survey data and confidential geo-coded violence data to investigate the associations between conflict, food security and wheat flour price shocks. As a first step, we map the geo-spatial distribution of food insecurity and conflict across provinces. Knowing the geographic distribution of food insecurity can aid in targeting resources to vulnerable populations, for example, through the placement of strategic grain reserves or the improved targeting of safety net programs. Such interventions are of particular importance during periods of high food prices. Conflict is most prevalent in a few provinces, with some provinces experiencing little to no conflict. Levels of food insecurity also vary greatly across the country, which is not surprising given Afghanistan's diverse terrain, climate, and agricultural zones. What is surprising, and in some contrast to the portrayal of the relationship in the existing literature, is that areas of high conflict are not the most food insecure; households located in the conflict-ridden provinces of the south have relatively lower levels of food insecurity, while households in the north and northeast suffer from very high levels of food insecurity. For example, in Balkh and Badakhshan, two northern provinces, over 50 percent of the population do not meet the minimum daily requirements of 2,100 kilocalories per person. In contrast, in both Kandahar and Helmand, southern provinces suffering from significantly more conflict, less than 30 percent of the population falls below this threshold. Thus from this simple mapping, conflict does not appear to be the major driver of food insecurity in Afghanistan.

Using simple correlation coefficients between food security (as measured by calorie intake and the real value of food consumed) and conflict (using various measures associated with violent incidents and the number of persons killed or injured), we find a very weak relationship, with mixed signs depending on the measures used. Using a simple bivariate regression model of conflict on food security, we similarly find mixed results. But once we move to a multivariate framework that takes into account household characteristics and key commodity prices, we find robust evidence that in Afghanistan levels of conflict and food security are negatively correlated.

Finally, we examine how conflict levels contribute to the impact of food price increases on household food security by estimating the differential price effects based on the level of conflict in 
the province where the household is located. The results indicate that households in provinces with higher levels of conflict experience muted declines in food security relative to households in provinces with lower levels of conflict, holding all other factors constant. This finding is consistent with the fact that households in conflict areas may be more disconnected from markets than households in non-conflict areas; thus the price effects for the former group are smaller. This analysis builds on D’Souza and Jolliffe (2012), who find that increases in wheat flour prices led to declines in household food security, but who do not consider dimensions of conflict in their analysis.

This paper is the first to assess empirically the association between food security and conflict in Afghanistan. It also brings a new dimension to the study of food price effects, as there is little empirical research from conflict countries on such topics. In the next section, we describe the data, define our measures of food security and conflict, and present descriptive statistics. In section three we present the spatial mappings of food insecurity and conflict. In section four we present our empirical model and results. The last section summarizes the key findings.

\section{Data}

We combine data from two primary sources: household and price data from the National Risk and Vulnerability Assessment (NRVA) 2007/08 and confidential geo-coded data on violent incidents from the United Nations Department of Safety and Security (UNDSS).

The NRVA 2007/08 was conducted by the Afghanistan Central Statistics Organization and the Ministry of Rural Rehabilitation and Development between August 2007 and September 2008. The frame used for drawing the sample was the 2003-05 national household listing - a listing of every house in the country; the sample was selected following a stratified, multi-stage design. The survey covered 20,576 households (about 150,000 individuals) in 2,572 communities. The effective sample size for our analysis is 20,483 households in 394 districts in all 34 provinces. $^{2}$

\footnotetext{
2 Thirty-two households were dropped due to missing female questionnaires, which include the consumption data. All of these households are located in four communities, suggesting systematic errors in field operations. Fifty-two households were dropped due to missing consumption data and seven households were dropped due to missing asset
} 
The NRVA 2007/08 survey was stratified implicitly over time, which ensures that the samples for each quarter reflect the overall composition of the country. ${ }^{3}$ This aspect of the design means that each quarter can be viewed as a representative sample, allowing us to measure seasonal variation in food security. ${ }^{4}$ This feature also allows us to exploit the price variation that is captured over the survey year, giving us additional power to measure how prices affect food security outcomes. ${ }^{5}$

Another key feature of the survey is the year-long fieldwork, which allowed coverage of conflict areas. Enumerators informally secured permission from local leaders in conflict areas and when a primary sampling unit (PSU) was considered too dangerous to interview at the scheduled time, it would be re-considered at a later date within the quarter, instead of replaced immediately. This flexible design helped to ensure a low replacement rate. While the majority of replacements were due to security issues, only 68 PSUs were replaced from the planned 2,441 PSUs in the sample design (less than $3 \%$ replacement rate). ${ }^{6}$ It is often difficult to obtain reliable data from conflict areas; thus the current analysis is able to provide a rare perspective on the relationship between food insecurity and conflict.

The survey includes detailed consumption information, which allows us to calculate several measures of food insecurity at the household level. The survey asks respondents about the amount and frequency of consumption of 91 food items from nine food groups over the previous week. The NRVA's broad coverage of foods, including seasonal varieties, allows more precise estimation of food consumption and calories than is possible in surveys with fewer items.

\footnotetext{
data. One household is missing data on household size and is dropped because per capita measures of consumption and food security cannot be calculated.

${ }^{3}$ Implicit stratification means that the frame was sorted both spatially and temporally to ensure that (with a systemic interval selection) the selected sample would be seasonally representative. See Kish (1965, p.235-6) for a discussion of implicit stratification.

4 Thus the sample can be thought of as a repeated cross-section.

${ }^{5}$ It is relatively unusual to have cross-section data that spans an entire year and has been temporally stratified. The stratification ensured that the household data provided representative estimates for quarterly subsamples, thus enabling us to identify the effects of the price increases on households. The 13-month time span was sufficiently long to ensure that there was significant variation in prices. If the time span had been shorter, the variation in prices likely would have been less (truncating or missing the price spike).

${ }^{6}$ Replacement PSUs were primarily selected from the nearest secure district
} 
Finally the NRVA included a district market price survey; local market prices on food items in the consumption module, along with the prices of domestic and imported grains and fuel, were collected during visits to the primary sampling unit area.

The geo-coded conflict data cover the survey timeframe from August 2007 to September 2008. UNDSS collects information on fatalities and injuries, as well as violent incidents more generally. According to the official U.N. definition, violent incidents include the following: abduction; air strike; armed clash; arrest; assassination; finding a weapons cache; confrontation/dispute; crime; demonstration; IED (improvised explosive device) detonation; IED discovered; information; intimidation; mine/UXO (unexploded explosive ordnance) incident; narcotic incident; stand-off attack; suicide attack; and other.

\subsection{Measures of food security}

We calculate two core indicators of food security for each household (incorporating population weights): per capita daily calorie intake and per capita monthly food consumption. These indicators relate to the access to food, a key pillar of food security (FAO, 2006). The former relates to the quantity of food consumed, whereas the latter incorporates information on both the quantity and the quality of food consumed since it includes prices (which can be correlated with quality).

Daily per capita calorie intake is calculated by dividing weekly total household calories by seven days and by the effective household size. The effective number of household members accounts for guests eating meals within the home, as well as household members eating meals outside the home. Food quantities were converted to kilocalories using the FAO Food Composition Tables for the Near East. ${ }^{7}$

The real value of food consumption (in Afghani) is calculated by combining quantity data from the consumption module with price data from a district price survey. Food consumption data include food bought, produced or obtained through other methods, e.g., food aid, gifts. Weekly values were multiplied by 4.2 to get monthly values. Prices were matched by month, item, and district. Since not

\footnotetext{
7 Spices and 'other' foods do not contribute to total calories. USDA sources were used for a few items that were not available in the FAO tables. For details, see: http://www.fao.org/docrep/003/x6879e/x6879e00.HTM
} 
all food items were available in all district markets at all times of the year, we imputed the missing elements to obtain a complete price matrix. ${ }^{8}$ We calculated average prices for domestic and imported varieties separately to account for differences in price and quality between domestic and imported wheat and rice. ${ }^{9}$ The value of expenditure on food away from home (approximately $2 \%$ of household food expenditure) is included in the calculation of food consumption, but not included in the calculation of calorie intake since quantity data on such food were not collected.

We adjust the food consumption estimates to take into account spatial and temporal variation in prices in order to identify correctly those households that fall below the food poverty threshold (described below) and, in the regression analysis, to estimate the impact of the price increases on real values. We use a Laspeyres price index estimated by quarter for each region. ${ }^{10}$ Real food consumption is relative to the chosen base: urban areas in the Central region in quarter 1; the capital, Kabul, is located in the Central region.

\subsection{Measures of conflict}

To measure the level of conflict in a province, we use (i) the number of individuals killed or injured (denoted as fatalities and injuries) and (ii) the number of violent incidents. Each measure is calculated by province for each survey quarter. We adjust the measures by population (dividing by province population, in tens of thousands) and by area (dividing by province square kilometers, in thousands) in order to capture the intensity of conflict within each province; these adjustments provide per 10,000 persons and per 1,000 square kilometers conflict measures, respectively.

\subsection{Descriptive statistics}

Table 1 displays the measures of food security over the four quarters of the NRVA survey. The raw data reveal that household access to food declined over the survey year. The nominal value of food

\footnotetext{
${ }^{8}$ The imputation process filled in missing values using the first-feasible methodology according to the following order: 1) median of the 20 nearest neighboring districts of that month;2) province median of that month; 3) national median of that month; 4) median price of 20 neighboring districts of the quarter; 5) province median of that quarter; and 6 ) national median of that quarter.

${ }^{9}$ The survey includes questions on the percentages of imported wheat and rice consumed; these percentages are used to calculate total expenditure for these items.

10 The food price index is based on a reference bundle of goods consumed by relatively poor households; the reference bundle was constructed to reflect regional diversity in consumption patterns. There are eight regions in Afghanistan, and they are defined in Islamic Republic of Afghanistan and World Bank (2011b).
} 
consumption is basically flat over the year. But once we account for the surge in food prices (deflating by a Laspeyres price index), we observe a large decline (over 30\%) in the real value of food consumption. Calorie intake also declines by approximately 17 percent over the year. Many Afghan households live in a state of food insecurity. In the first quarter, approximately 24 percent of Afghan households were unable to achieve 2,100 kilocalories per person per day; by the fourth quarter, over 35 percent were in this precarious situation.

In Afghanistan, conflict is quite seasonal, though it does occur throughout the year. The "fighting season" is usually concentrated in the spring and summer months, as fighting is difficult during winter months given the harsh climate and mountainous terrain. We observe this pattern in the UN data, which show that quarters one (August-October 2007) and four (Jun-Sept 2008) of the survey timeframe were the most violent (table 2). In quarter four, there were nearly 300 fatalities and injuries in 196 separate incidents. In the quarter preceding this, there were 131 fatalities and injuries in 116 separate incidents. In addition to the high level of variation in conflict across the quarters, there was also a lot of variation across provinces within quarter, which we discuss below.

Over the survey year (August 2007 - September 2008), based on the Government of Afghanistan Consumer Price Index, food prices increased by approximately 40 percent, in contrast to nonfood prices, which increased by only 10 percent (Islamic Republic of Afghanistan and the World Bank, 2010). The NRVA price data show increases in the prices of various important foods and kerosene (cooking fuel) (table 4). The largest price increase is observed for wheat flour - the Afghan staple, which contributes approximately 54 percent to calorie intake and 35 percent to food expenditure. From quarter one to quarter four, wheat flour prices doubled, signifying a serious reduction in purchasing power for households that spend, on average, about 60 percent of the total budget on food.

\section{Mapping food insecurity and conflict across Afghanistan}

We present a series of maps that depict levels of food insecurity and conflict by province. In lieu of grouping provinces by average calorie intake or average real value of food consumption, we calculate 
the percentage of households that fall below policy-relevant thresholds for each food security measure. Such spatial descriptions are informative from a policy perspective because they take into account the depth of food insecurity in each province - that is, these measures of food insecurity provide information on the distribution of food insecurity within each province instead of just mean values. For each province, we calculate the percentage of households that fail to meet the standard threshold of 2,100 kilocalories per person per day. We denote these households as calorie-deficient. We define those households that are unable to meet the costs of the minimum basic food requirements of 2,100 kilocalories per day per person as food poor.

Food poverty is a core component of poverty indicators (Islamic Republic of Afghanistan et al., 2011a; Islamic Republic of Afghanistan et al., 2011b). If the real per capita value of monthly food consumption is below the food poverty line, then all individuals in the household are considered to be food poor. To establish the food poverty line we follow the guidelines set forth by the Islamic Republic of Afghanistan and the World Bank (2010). This threshold represents the minimum cost of obtaining 2,100 calories based on the consumption patterns of the "relatively poor". The relatively poor are defined for each region as those individuals whose consumption level is between the 20th and 50th percentiles of real per capita total consumption in each region. The regional subsamples were aggregated to create a national typical food bundle for the relatively poor. The inclusion of households from each region in the construction of the reference food bundle ensures that the bundle reflects the regional diversity in consumption patterns. And aggregating the subsamples together into one bundle ensures that minimum food quantities and types are the same for everyone in the country. Therefore the food bundle reflects regional variation, but also anchors the definition of minimum needs to be the same for everyone. If the reference bundle varied across regions, it would be more difficult to assert that the utility derived from the bundle is constant. For example, if there were two reference bundles, and one had more meat than the other, it would be reasonable to think that the more meat intensive bundle reflected a higher level of quality or higher utility. The estimated cost of this scaled food bundle is 687 Afghani per capita, per month when priced in terms of quarter 1, Central region urban prices. ${ }^{11}$ In real terms, the cost of the food poverty line is the same for everyone. In nominal terms, it differs across regions and over quarters. Households whose real monthly per capita food consumption is below 687 Afghani are designated as food poor.

11 The Central region consists of Kabul, Kapisa, Parwan, Wardak, Logar, and Panjshir provinces. 
Both calorie deficiency and food poverty vary across the country (figures 1 and 2). In seven of the 34 provinces, over half of the households are calorie-deficient. Most of the worst off provinces in terms of calorie deficiency are concentrated in the east and the northeast, with the exceptions of Nimroz and Badghis provinces. Most northeast and central provinces have high rates of food poverty (except Kabul). The southwest provinces of Nimroz, Helmand, Kandahar, and Farah have among the lowest rates of food poverty in the country. Badakhshan and Laghman are the worst off provinces, with calorie deficiency and food poverty rates of over 60 percent.

The mappings of fatalities and injuries per 10,000 persons and violent incidents per 10,000 persons support government reports and media coverage on the country's most insecure areas (figures 3 and 4). While many provinces experienced some violence during the survey timeframe, the level of conflict was higher in the southern provinces of Helmand and Kandahar and in their neighboring provinces of Uruzgan, Zabul, Ghazni and Paktika than in other regions. (Helmand and Kandahar provinces are the focus of US-led military activities.)

These maps suggest that, at least in the case of Afghanistan, conflict does not seem to be the predominant driver of food insecurity. For example, the southwest provinces, where much conflict takes place, have relatively low levels of food poverty. And very poor, food insecure provinces like Badakhshan and Balkh had few violent incidents during this period. This fact may be surprising to some donors and scholars who presume that households in conflict areas are more food insecure than those in non-conflict areas or that conflict is a driving factor in food insecurity. For example, Maplecroft, a risk management firm, states, "Conflict is also a major driver of food insecurity and the ongoing violence in Afghanistan and DR Congo is largely responsible for the precarious food security situation in both countries," (Maplecroft, 2010). The FAO rates conflict as the most common cause of food insecurity (FAO, 2005), though such conflict most likely refers to prolonged periods of civil or interstate war.

Taken together, these maps provide a snapshot of food insecurity and conflict across Afghanistan during 2007/08. However, given the variation across provinces and, perhaps, within provinces, it is difficult to appreciate the association between these variables through maps alone. When we estimate the correlation coefficients of the conflict variables with our household measures of food security - per capita daily calories and per capita monthly food consumption - we find mixed signs, 
with little evidence of a correlation (i.e., correlation coefficients close to zero). The correlation between conflict and calories is always negative, but the correlation between conflict and food consumption is positive when conflict is measured by the number of killed and injured. In the next section we present an empirical model that allows us to test the statistical association between household food security and provincial levels of conflict while controlling for other potential confounding factors.

\section{Empirical Model and Results}

The objective of our empirical analysis is two-fold. First, we estimate the statistical association between household food security and levels of conflict. Second we estimate potential differential effects of wheat flour prices on household food security based on the level of conflict in the household's province.

We begin with the simplest specification - a bivariate OLS model (providing information conceptually similar to the descriptive analysis in the mappings above):

$\log \left(f s_{h}\right)=\beta_{0}+\beta_{1} \log \left(\operatorname{conflict}_{p q}\right)+\varepsilon_{h}$

where $b$ denotes household, $p$ denotes province, and $q$ denotes quarter. $f_{s}$ is one of the two measures of household food security described above. Conflict is one of the four measures described above, aggregated by province and by quarter. $\varepsilon$ is an idiosyncratic error term; robust standard errors are estimated with a standard Huber-White sandwich estimator to account for the clustered sample design and they are also adjusted for stratification. If $\beta_{1}$ is positive, it suggests that households in provinces with higher levels of conflict are more food secure; if it is negative, it suggests that households in provinces with higher levels of conflict are less food secure.

The top panel of Table 4 displays regression results from the bivariate model (eq1). The coefficients are statistically significant but have mixed signs. The coefficients in the calorie regressions are all negative, but two of the coefficients (columns 5 and 6) in the food consumption regressions are positive. This model, however, does not control for other (potentially confounding) factors that 
explain food security levels; if some of these omitted variables are correlated with conflict as well, then the coefficient on the conflict variable will be biased. For example, households living in mountainous areas may suffer from higher levels of food security since they may have difficulty accessing markets in remote areas; such topography may also influence the level of conflict. ${ }^{12}$ As a first step in incorporating such variables, we include household and district characteristics and the prices of key commodities. The basic multivariate model is as follows:

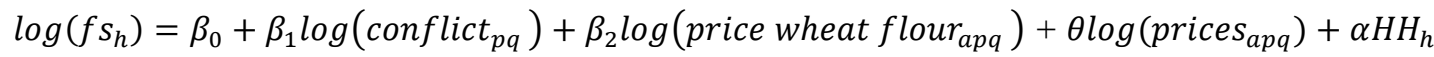

$$
\begin{aligned}
& +\delta D I S T_{d q}+\varepsilon_{h}
\end{aligned}
$$

where $a$ denotes area (urban or rural) and $d$ denotes district. Price wheat flour is the price of domestic wheat flour, which is of interest given its important role in the Afghan diet and the large surge in its price. Prices represents a vector of commodity prices, $H H$ represents a vector of household characteristics and DIST represents a vector of district-level variables.

We control for contemporaneous price increases in other important commodities since household purchasing decisions are based on relative prices. The price vector includes the prices of milk, lamb, rice, and vegetable oil - key foods that represent a large portion of household food expenditure and kerosene, a commonly used cooking fuel. ${ }^{13}$

We include the following household characteristics: log values of durable assets, housing and livestock; age of household head; a dummy for households in which heads are literate; and a dummy for households in which heads are married. We also include dummies, at the district level, for rural locations and for topography (plateau and mountainous areas, with plains excluded).

The asset values (in Afghani) are intended to control for wealth effects and are assumed to be quasifixed in the short run. The value of durable goods is estimated based on a detailed inventory of household assets; it accounts for depreciation and the opportunity cost of the funds tied up in the good. For housing, we estimate a hedonic model for housing based on characteristics of the

\footnotetext{
12 This is particularly relevant in Afghanistan, which has a lengthy history of mountain warfare.

13 More specifically, the relatively poor $\left(20^{\text {th }}\right.$ to $50^{\text {th }}$ quantile of the total consumption distribution) spend eighty percent of their food expenditure on these five food items (including wheat flour).
} 
structure, as well as the location, and derive an imputed rental value from this. ${ }^{14}$ Table 5 includes summary statistics for all control variables by quarter.

The middle panel of Table 4 displays the coefficient of interest - on the log of conflict - from the multivariate regression model (eq2). (Appendix tables A1-A2 display the full set of coefficients.) The coefficients are negative and significant in all specifications. Those coefficients that were positive in the bivariate model are now negative, suggesting that, as expected, the simplistic model suffered from omitted variable bias. The results (shown in appendix tables A1 and A2) also indicate that wheat flour price increases are associated with a decline in food security for Afghan households. This result is consistent with much of the empirical household literature on the impact of food price increases, which finds declines in household wellbeing (e.g., increases in poverty, decreases in maternal and child health, etc.). The results are robust to the inclusion of household composition variables (number of men, women, and children) that control for differences in consumption requirements between children and adults and for economies of scale in consumption. ${ }^{15}$

Another potential source of bias could stem from simultaneity, i.e., conflict and food security could be determined jointly or food security could influence conflict. To explore this concern, we employ an instrumental variables (IV) approach. We use a two-quarter lag of conflict as an instrument for current conflict. ${ }^{16}$ Instrument validity hinges on two assumptions. First, current and past levels of conflict are correlated, which is the case in the data. And second, conflict occurring two quarters ago does not affect (directly) current levels of household food security; it only affects current food security through its association with current conflict. It is likely that current conflict affects current food security, for example, by preventing travel or disrupting trade. To the extent that this is the key pathway through which conflict affects food security, then the two-quarter lag conflict instrument is a valid tool to assess the concern about endogeneity bias. It is also possible though that past conflict affects current food security, for example, through the destruction of agricultural resources. If this is

\footnotetext{
14 The log value of durable goods is a self-assessed valuation based on a list of 13 assets including items such as stoves, refrigerators, radios, sewing machines, and bicycles. The estimated housing value is the log of imputed, monthly rental value based on a hedonic model of the housing structure. For details of the estimation, see Islamic Republic of Afghanistan and the World Bank (2011a).

15 An alternative approach to account for such differences employs equivalency scales, which take into account nutritional requirements based on age and, sometimes, gender when calculating per capita measures. An advantage of including household composition in the specification, rather than using equivalence scales, is that this method allows the data to specify the parameterization of the scales.

${ }_{16}$ Earlier data were not available from the U.N. Department of Safety and Security.
} 
the key pathway through which conflict affects food security, then the exclusion restriction is violated and the two-quarter lag instrument is not valid. Therefore the results of the IV regressions must be taken with caution.

The bottom panel of Table 4 displays the coefficients of interest - on the log of conflict - from the IV regressions. The results show strong patterns. The coefficients are significant and of the same sign (in seven out of eight cases, the coefficients are larger in magnitude than the OLS coefficients). We interpret these findings as providing partial evidence that the OLS estimates in Table 4 do not suffer significantly from endogeneity bias and that the coefficient on the log of conflict reflects the influence of conflict on household food security.

Next we turn to the relationship between food security, food price increases, and conflict. To the best of our knowledge, the literature on the impact of food price increases on household wellbeing has not incorporated any dimensions of conflict. It is possible that food price effects are more pronounced in conflict areas given the poor food production and distribution systems; however households in conflict areas may not be as engaged in the market as those in non-conflict areas and thus the food price effects may be less pronounced. To examine these hypotheses, we include an interaction term that allows the effect of the wheat flour prices to vary based on the level of conflict in a province. The specification is as follows:

$\log \left(f s_{h}\right)=\beta_{0}+\beta_{1} \log \left(\right.$ conflict $\left._{p q}\right)+\beta_{2} \log \left(\right.$ price wheat flour $\left.r_{a p q}\right)$

$+\beta_{3} \log \left(\right.$ price wheat flour $\left._{a p q}\right) X \log \left(\right.$ conflict $\left._{p q}\right)+\theta \log \left(\right.$ prices $\left._{a p q}\right)+\alpha H H_{h}+\delta D I S T_{d q}+\varepsilon_{h}$

The coefficient $\beta_{3}$ represents the additional price effect due to the level of conflict in the household's province. Columns (1), (3), (5), and (7) in Tables 6 and 7 display the coefficients of interest from estimating equation 3. Regardless of the measure of food security or the measure of conflict, the coefficient on the interaction term is positive and statistically significant. Thus, holding all other factors constant, an increase in wheat flour prices leads to slightly smaller reductions in food security in areas with more conflict than in areas with less conflict. This result is consistent with the interpretation that households in conflict-afflicted areas are less connected to markets and therefore may not be as affected by price increases as those households in less conflict-afflicted areas. This 
finding might also indicate that households in conflict-afflicted areas have learned to cope more effectively with shocks, whether they arise from conflict, price increases, or other events.

While we can only offer hypotheses as to why the price interaction effect tempers the negative correlation between conflict and food security, it is a finding that has some policy implications. A concern of governments and aid agencies is that food price shocks may have larger adverse effects in areas of conflict. If this were the case, policy responses would be more complicated given the additional costs and logistical difficulties of providing food assistance to those areas. However, our finding suggests that the adverse effects of price shocks on food security are not worse in conflictafflicted areas, but rather appear to be modestly less severe. The implication is that policies specifically designed to address price shocks need not place more emphasis on conflict zones.

To obtain the total marginal effect of the log of wheat flour price, we need to sum the coefficients of the base effect, $\beta_{2}$, and the interaction effect, $\beta_{3}$, for a given level of conflict (i.e., holding conflict constant). Instead of choosing an arbitrary level of conflict (typically the average, which provides the marginal effect at the mean), we calculate the average marginal effect by calculating the marginal effect of the log of wheat flour prices evaluated at each observation and then taking the average (using survey weights); we conduct analogous calculations for the log of conflict. (The average marginal effects are shown at the bottom of tables 6 and 7.) In all cases, the average marginal effects are negative and statistically significant.

While equation 3 incorporates several control variables, there are factors at the province-level that may be correlated with both household food security and conflict, and thus represent potential additional sources of omitted-variable bias. For example, poverty, which is negatively correlated with household food security since poor households often lack the resources to access food, may be positively or negatively correlated with internal conflict. Collier and Hoeffler (2004) propose that a major driver of conflict, particularly civil conflict (which is not funded through taxation as with inter-government conflict), is the ability to finance rebellion; thus groups in better off areas (with access to resources) may be more prone to violence. On the other hand, it is possible that economic grievances drive people to rebel (Blattman and Miguel, 2010). Therefore we include the provincial 
poverty rate in our model; we also include two other province-level variables for which we have data: the underemployment rate and the Gini coefficient of inequality. ${ }^{17}$

The coefficients on these province-level variables are negative, as may have been expected, and mostly significant. There is little change in the coefficients on the interaction effect. And the average marginal effects of the $\log$ of wheat flour prices and the log of conflict are largely robust to the inclusion of these variables. These three province-level variables may not capture all possible omitted province-level variables that could bias our results and so as an additional test we include province fixed effects (in lieu of the province-level variables). (Results are available upon request.) The coefficients on the interaction effect remain positive and the average marginal effects of the log of wheat flour prices remain negative. The average marginal effects of the log of conflict variables remain negative in the calorie regressions, but are positive in the food consumption regressions. This inconsistency is not surprising since the conflict measures are calculated by province for each quarter, thus province fixed effects absorb much of the variation in the conflict variables. Thus in the fixed effects regressions, the coefficients on the log of conflict are identified solely from differences in conflict levels across quarters, which are not as large as differences across provinces. ${ }^{18}$

As above, we run an instrumental variables model for equation 3; we instrument the log of conflict and the interaction term with the log of lagged conflict and the log of lagged conflict interacted with the $\log$ of wheat flour price. The results are robust in the calories regressions, but not in the food consumption regressions. (Results are available upon request.) Since both instruments are derived from the same variable (log of lagged conflict), we suspect that they are too weak to identify separately the two endogenous variables. The average marginal effects of the log of conflict - while at times very large - are statistically significant and negative in all cases. Again, given the potential violations of the exclusion restriction, these results should be interpreted as suggestive, not conclusive.

\footnotetext{
${ }^{17}$ We use provincial statistics as reported in Islamic Republic of Afghanistan and World Bank (2011b). Underemployment is defined as those who work on average less than 35 hours, per week divided by the total labor force. The exact definition of underemployment would require assessing workers' willingness to work for additional hours. Unfortunately, the survey instruments do not allow us to distinguish between those who are "underemployed" and those who willingly work "part-time". The Gini coefficient is a measure of inequality of per capita consumption, and the poverty rate is estimated following the cost-of-basic-needs methodology. For details, see Islamic Republic of Afghanistan and World Bank (2011a).

18 According to analysis of variance analysis (ANOVA), the majority of variation in the conflict variables comes from differences across provinces rather than differences within provinces over time.
} 
Finally we test the robustness of our coefficients of interest to an alternative classification of "violent incidents". Above we use the U.N. definition, which includes several events that may not be associated with elevated levels of conflict or violence, namely, 'arrest', 'demonstration', 'information', 'narcotic incidents', and 'other'. We recalculate the measures of conflict excluding such incidents. The results (available upon request) are qualitatively the same.

\section{Conclusions}

Extended conflicts can disrupt markets, destroy resources, and take a psychological toll on the population. In this paper, we investigate the relationship between conflict (as measured by fatalities and injuries or violent incidents per 10,000 persons or per 1,000 square kilometers) and household food security (as measured by per capita calorie intake and the real value of per capita food consumption) in Afghanistan. Descriptive analyses using spatial mappings and bivariate regression models produce inconsistent results. However in a multivariate regression framework, after controlling for important household characteristics, as well as the prices of important food items, we find evidence of a strong, negative relationship between conflict and household food security. The patterns in Afghanistan are consistent with research that emphasizes the negative impact of conflict on food insecurity (see, for example, Teodosijevic (2003).

In countries afflicted by conflict, economic shocks (e.g., food price spikes) or natural disasters (e.g., drought) can have deleterious effects on already vulnerable populations. For households in Afghanistan, most of who spend the majority of their budgets on food, the 2008 spike in wheat flour prices represented a sudden and drastic decline in purchasing power. Overall, we find that the average marginal effect of the log of wheat flour prices is negative and statistically significant; as was the case in many other developing countries, the 2008 spike in staple food prices represented a substantial decline in wellbeing for Afghan households. We examined the consequences of this shock, focusing our attention on differences based on the level of conflict in a province and finding that households living in provinces with higher levels of conflict experienced more muted declines in food security than households living in provinces with lower levels of conflict. This may have been due to more limited market engagement by the former. The mechanisms behind these findings are 
largely unknown, underscoring the need for further data collection and research on conflict countries - particularly related to the causes of food security and changes in food security over time.

\section{References}

Blattman, C., Miguel, E., 2010. Civil War. Journal of Economic Literature 48, 3-57.

Bora, S., Ceccacci, I., Delgado, C., Townsend, R., 2010. Food Security and Conflict, World Development Report 2011 Background Paper. World Bank, Washington, D.C.

Collier, P., Hoeffler, A., 2004. Greed and Grievance in Civil War. Oxford Economic Papers 56, 563595.

D'Souza, A., Jolliffe, D., 2012. Rising Food Prices and Coping Strategies: Household-Level Evidence from Afghanistan. Journal of Development Studies 48.

FAO, 2005. Assessment of the World Food Security Situation. Food and Agricultural Organization, United Nations, Rome.

FAO, 2006. Food Security. Food and Agricultural Organization, United Nations.

Giustozzi, A., Ibrahimi, N., 2012. Thirty Years of Conflict: Drivers of Anti-Government Mobilisation in Afghanistan, 1978-2011, Afghanistan Research and Evaluation Unit Issues Paper. Afghanistan Research and Evaluation Unit Kabul.

Islamic Republic of Afghanistan, Central Statistics Organization (CSO), World Bank Economic Policy and Poverty Sector, 2011a. Setting the Official Poverty Line for Afghanistan, Kabul.

Islamic Republic of Afghanistan, Ministry of Economy, World Bank Economic Policy and Poverty Sector, 2011b. Afghanistan Provincial Briefs, Kabul.

Islamic Republic of Afghanistan, Ministry of Economy, and the World Bank Economic Policy and Poverty Sector, 2010. Poverty Status in Afghanistan: A Profile Based on the National Risk and Vulnerability Assessment (NRVA) 2007/08. Islamic Republic of Afghanistan, Ministry of Economy, and the World Bank Economic Policy and Poverty Sector, Kabul.

Johnecheck, W., Holland, D.E., 2007. Nutritional status in postconflict Afghanistan: Evidence from the National Surveillance System Pilot and National Risk and Vulnerability Assessment. Food and Nutrition Bulletin 28, 3-17.

Kish, L. 1965. Survey Sampling. New York: Wiley.

Maplecroft, 2010. African nations dominate Maplecroft's new Food Security Risk Index - China and Russia will face challenges. Maplecroft, Bath. 
Messer, E., Cohen, M.J., 2006. Conflict, Food Insecurity, and Globalization, Food Consumption and Nutrition Division Discussion Paper. International Food Policy Research Institute, Washington, D.C., p. 45.

Messer, E., Cohen, M.J., Marchione, T., 2002. Conflict: A Cause and Effect of Hunger, Environmental Change and Security Project Report. Food and Agriculture Organization, United Nations, Rome, p. 16.

Teodosijevic, S., 2003. Armed Conflicts and Food Security, ESA Working Paper. Food and Agriculture Organization, United Nations, Rome, p. 30. 